\title{
INFRARED INVESTIGATION OF THE SEQUESTRATION OF TOLUENE VAPOR ON CLAY MINERALS
}

\author{
Meei-Ling Chang, $* \dagger$ Shian-Chee Wu, $\neq$ Pei-Jen Chen, $\neq$ and Shu-Chun Cheng $\neq$ \\ $\dagger$ Department of Environmental Engineering, Van Nung Institute of Technology, Number 1, Van Nung Road, \\ Chung-Li Tao-yuan, 320, Taiwan, Republic of China \\ †Institute of Environmental Engineering, National Taiwan University, Number 71, Chou-shan Road, Taipei, 106, Taiwan, Republic of China
}

(Received 17 June 2002; Accepted 11 January 2003)

\begin{abstract}
The Ca-exchanged clays were used to investigate the sorption of toluene under both high and low relative humidity conditions. According to the observed rates of sorption and desorption and the Fourier transform infrared (FTIR) spectra of sorbed toluene, the sorbate molecules on clays can be divided into three categories: labile (gaslike) phase, slow sorption (liquidlike) phase, and resistant-to-desorption phase with sorption/desorption time scales of less than $30 \mathrm{~min}$, several hours, and several weeks, respectively. Aging changed the spectroscopic characteristics of the sorbed sorbates and contributed to the irreversibility of the sorption under both high and low relative humidity. Irreversibly sorbed portions of the sorbates and new characteristic peaks identified with FTIR spectrometry suggest the existence of chemical transformation of sorbed species under both high and low relative humidity conditions. It is suggested that the clay minerals, acting as catalysts, may contribute to abiotic natural attenuation of volatile organic aromatic hydrocarbons in soils.
\end{abstract}

Keywords-Clays Toluene Sorption/desorption Aging Chemical transformation

\section{INTRODUCTION}

Sorption kinetics of organic pollutants in soils, especially those with a time scale similar to or longer than the contact time of an organism or a fluid with the soil, have significant effects on the bioavailability, the fate, the potential of human health risk, and the ease of the cleanup of contaminants in soils [1]. Aging (long-term contact of organic pollutants with sorbents) increases the possibility for development of strong sorbate-sorbent interaction or chemical transformation of sorbates that have high energies of activation, Alexander [2] and Loehr and Webster [3] have reviewed studies in which sequestered chemicals in soil become more resistant to desorption. The biodegradation rate of phenanthrene declined with time of aging in soils [4]. The sequestration of sorbates by soils impacts both the sorbate bioavailability and the sorption reversibility. However, the real causes of the desorption resistance related to long-term contact time have not been explored adequately.

The assumption of instantaneous equilibrium has been found to not always be valid for predicting the transport of a pollutant in soils, which indicates that kinetics, in addition to thermodynamics, governs the transport process. The time scale for reversible sorption is usually short (e.g., $1 \mathrm{~d}$ for aniline and $\alpha$-naphthylamine [5] and a few hours at the most for volatile organic hydrocarbons on soils [6]) but is unlimited if irreversible binding and/or transformation are involved [2]. Initially rapid sorption/desorption followed by slow sorption/ desorption has been widely observed for hydrophobic organic compounds (HOCs) from soil/sediment [6-9]. A kinetic model consisting of two separate compartments has been used to describe the desorption data [7-9]. However, the interpretation of macroscopic data considering HOCs diffusing into and out

* To whom correspondence may be addressed (mlchang@cc.vit.edu.tw). of soil/sediment was complicated by mixed sorption phenomena. Microscale analytical characterizations are needed to advance the knowledge of HOCs' impacts on the environment [1].

Because of the large surface area and the complicated network structure, the clay component in soil is an important inorganic constituent responsible for the sorption of organic compounds. Sorption of arenes, like anisole, xylene, toluene, and benzene, onto transition-metal-, usually $\mathrm{Cu}-$, exchanged montmorillonite and smectite under $\mathrm{P}_{2} \mathrm{O}_{5}$-dried conditions $[10,11]$ or conditions where both sorbent and sorbate were refluxed in $n$-hexane for up to $48 \mathrm{~h}[12,13]$ resulted in the formation of irreversibly chemisorbed products. Chemisorption of $p$-xylene on self-supporting $\mathrm{Cu}$-exchanged montmorillonite film has been identified with Fourier transform infrared/ultraviolet-visible spectra by Johnston et al. [14]. The authors suggested that the directly coordinated water on the copper must have been replaced by a xylene molecule so the ligand position of the interlamellar copper might have been exposed to the $\pi$ electrons of a benzene ring. Therefore, the single electron transfer process triggered the chemisorption reaction. However, Hinedi et al. [15] reported some chemisorbed products of benzene sorption on $\mathrm{Cu}$-montmorillonite even under $100 \%$ relative humidity. The results of the sorption experiments involving benzene, butyl benzene, ethyl benzene, and trichloromethane on organoclay indicated that hydrophobic organic pollutants were sorbed primarily on hydrophobic siloxane surface, which was only slightly covered by water $[16,17]$; that is, many siloxane sites are available for hydrophobic organic adsorbates even in the presence of water.

The previously mentioned studies in the literature reveal the importance of clay as a mediator for the transformation of pollutants. Under very dry or heated conditions and with transition-metal-saturated clay, chemical transformations were observed over a short period of time. However, neither the de- 
Table 1 . Some properties of clay minerals ${ }^{\mathrm{a}}$

\begin{tabular}{llll}
\hline Clay minerals & Kaolinite & Ca-montmorillonite & Illite \\
Abbreviations & KGa-2 & STx-1 & IMt-1 \\
Origins & Washington County, GA, USA & Gonzales County, TX, USA & Silver Hill, MT, USA \\
Cation exchange capacity $(\mathrm{meq} / 100 \mathrm{~g})$ & 2.0 & 84.4 & $87^{\mathrm{b}}$ \\
IR spectroscopy $\left(\mathrm{cm}^{-1}\right)$ & $1,100($ split $)$ & $866-1300$ & $866-1230$ \\
Specific surface area $\left(\mathrm{m}^{2} / \mathrm{g}\right)$ & $10.5 / 9.5^{\mathrm{b}}$ & $83.7 / 80.8^{\mathrm{c}}$ & $51.2^{\mathrm{d} / 47.3^{\mathrm{c}}}$ \\
Organic carbon content $(\%)^{\mathrm{c}}$ & 0.02 & 0.03 & 0.03 \\
\hline
\end{tabular}

${ }^{a}$ Properties are selected from Olphen et al. [27] unless marked.

${ }^{\mathrm{b}}$ Weissmahr et al. [28].

${ }^{c}$ Measured values of this study using Brunauer-Emmett-Teller/nitrogen (BET/ $\left.\mathrm{N}_{2}\right)$ method and elemental analysis.

${ }^{\mathrm{d}} \mathrm{Xu}$ et al. [18].

hydrated condition nor the transition-metal-modified clay is commonly found in the natural environment. Studies using normal clay under humid conditions are needed. Furthermore, the mechanism for the development of slow rates and irreversibility of desorption by aging is still unclear. Therefore, the objective of this study is to investigate the long-term sorption kinetics and mechanisms of toluene on natural clay saturated with calcium under both low relative humidity and high relative humidity with the focus on the sorbate behavior at the molecular level. Since calcium is one of the most abundant elements in soil, calcium-exchanged clay, rather than the commonly used transition-metal-exchanged clay, was used. Thin clay films were used in this study to reduce the effects caused by toluene diffusion into or out from clay film, which could complicate the sorption phenomena. The sorption process was monitored on-line by using infrared (IR) spectrometry. The observed spectroscopic data were interpreted at the molecular level. Infrared spectra provide insight on in situ sorption. The major purpose of using IR spectrometry is to monitor the progress of sorbate phases on the sorbent rather than to detect the desorption vapors diluted by purging gas in the experiment. Our finding of what appears to be abiotic transformation of toluene on Ca-exchanged clay under both low relative humidity $(\mathrm{RH})$ and high $\mathrm{RH}$ has environmental significance and has not been observed before.

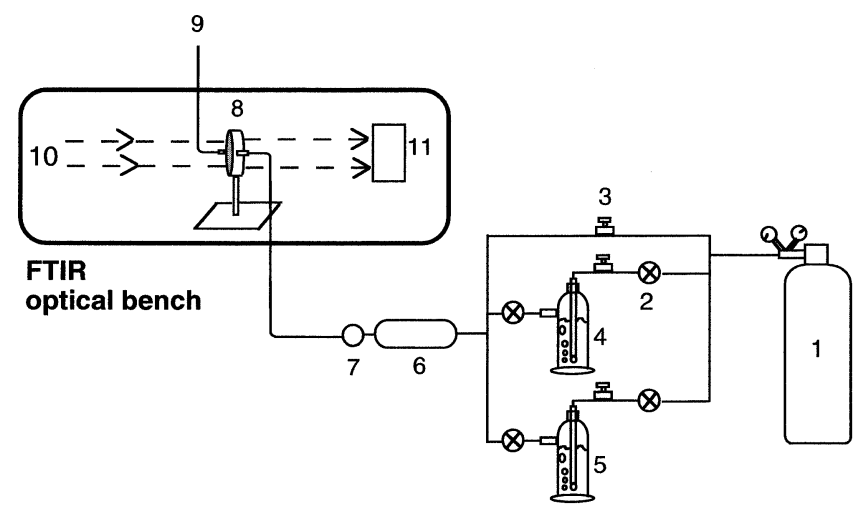
1. HC-free N2 gas
2. on-off valve
3. mass flow controller
4. toluene liquid
5. water
6. mixing chamber

\section{GC sampling port}

8. clay sample inside the $\mathrm{ZnSe}$ window

9. gas vent

10. IR source

11. MCT detector

Fig. 1. Schematic diagram of the apparatus for the sorption experiments. FTIR = Fourier transform infrared, $\mathrm{HC}=$ hydrocarbon, $\mathrm{GC}$ = gas chromatography, $\mathrm{IT}=$ infrared, $\mathrm{MCT}=$ mercury cadmium telluride.

\section{MATERIALS AND METHODS}

\section{Clay pretreatment}

Clay minerals used in this study were obtained from the Source Clay Mineral Repository of the Clay Minerals Society (Department of Geology, University of Missouri, Columbia, MO, USA).

Samples were pulverized with a ball mill, then treated with an acidified mixture of $35 \% \mathrm{H}_{2} \mathrm{O}_{2}$ and $1 \mathrm{M} \mathrm{NaCl}$ solution (1: 9) with $\mathrm{pH}$ adjusted to 3 to remove natural organic matter and amorphous impurities. The washing procedure was repeated twice, and the clay was then washed several times with Milli$\mathrm{Q}$ water (Millipore ${ }^{\circledR}$, Bedford, MA, USA) to remove excess $\mathrm{H}_{2} \mathrm{O}_{2}$ and $\mathrm{NaCl}$.

Clay particles with sizes smaller than $2 \mu \mathrm{m}$ in the supernatant were collected after the settlement of larger particles in Milli-Q water. The procedure was repeated several times to obtain a sufficient amount of clay with the desired particle size range. To make homoionic $\mathrm{Ca}$-saturated clay, the clay suspension was transferred into a polypropylene centrifuge bottle and washed several times with $250 \mathrm{ml}$ of $0.1 \mathrm{M} \mathrm{CaCl}_{2}$ solution and then washed with Milli-Q water to remove the excess salts. The effluent was tested with $\mathrm{AgNO}_{3}$ solution to ensure the absence of $\mathrm{Cl}^{-}$. The resulting clay was dried using a freeze-dryer [18] and was then stored under ambient laboratory temperature. The organic carbon content of the clay was determined by an element analyzer (Perkin-Elmer CHN-2400, Norwalk, CT, USA) after the treatment with $1: 1 \mathrm{H}_{3} \mathrm{PO}_{4}$ solution to remove inorganic carbon. Selected properties of the clay samples are summarized in Table 1.

\section{Sample preparation and experimental design for IR experiments}

Figure 1 shows the sorption experimental apparatus. $\mathrm{ZnSe}$ (International Crystal Laboratory, Garfield, NJ, USA) plates with diameters of $32 \mathrm{~mm}$ and thickness of $2 \mathrm{~mm}$ were overlaid with 0.7 to $0.8 \mathrm{ml}$ of homoionic calcium-clay suspension. A clay film was formed after being dried in a desiccator. A gas cell with a path length of $1 \mathrm{~cm}$ and internal volume of $5 \mathrm{~cm}^{3}$ had two $\mathrm{ZnSe}$ windows, one of which was coated with a clay film on the inner side, and was fixed on a cell stand in the light path of the spectrometer. This design allowed the spectra to be acquired instantaneously while a continuous flow of gas in contact with the sample was maintained. Spectra were obtained with an infrared spectrometer (BIO-Rad FTS 40, Randolph, MA, USA) equipped with a mercury cadmium telluride detector in a liquid nitrogen bath. Single-beam spectra obtained by averaging 200 scans at $2 \mathrm{~cm}^{-1}$ resolution were referenced against those of dry air and nitrogen of the optical bench background. Infrared transmission mode rather than a reflec- 
tion mode was used in this study for observing the sorption phenomena occurring in the whole clay sample and obtaining the absorbance intensity of the sorbed volatile organic compounds.

Before the toluene sorption experiment was initiated, the clay film in the cell was pretreated by purging with $\mathrm{N}_{2}$ or moistened $\mathrm{N}_{2}$ gas for more than 24 h to remove volatile organic chemicals and stabilized with the desired RH. The water occluded in the mineral crystal could not be thoroughly removed by extended $\mathrm{N}_{2}$ gas purging. The occluded water was identified by the characteristic spectra of water. The flow of gas was adjusted to $50 \mathrm{ml} / \mathrm{min}$ in all cases. Room temperature and the optical bench (sorption cell inside) were controlled at $25 \pm$ $1^{\circ} \mathrm{C}$. The toluene concentration of the inlet gas was maintained constant by a steady $\mathrm{N}_{2}$ flow passing through a toluene liquid in a gas washing bottle. The measured toluene concentration ranged from 202 to $270 \mathrm{mg} / \mathrm{L}\left(\mathrm{P} / \mathrm{P}_{0}\right.$ from $\left.0.3-0.4\right)$. The combination of the spectra of the clay, the toluene vapor, and the water vapor, obtained at the beginning of the adsorption experiment, was used as the background spectrum and was subtracted from the subsequently acquired sorption spectrum. A subtraction factor of 1.0 was used in all cases. The sorption/ desorption experiments were continuously monitored for more than $10 \mathrm{~d}$, and the $\mathrm{RH}$ of the flowing gas was controlled at below $3 \%$ for low $\mathrm{RH}$ and above $90 \%$ for high $\mathrm{RH}$ conditions. The RH was measured at the gas vent (component 9 denoted in Fig. 1) with a hygrometer (Oakton, Taiwan, ROC).

\section{RESULTS AND DISCUSSION}

\section{Sorption and desorption under low $R H$}

The total sorption experimental period was $14 \mathrm{~d}$ for kaolinite and illite and $16 \mathrm{~d}$ for montmorillonite. The FTIR spectra of sorbed toluene were analyzed by comparing with spectra of toluene liquid and toluene vapor in a $\mathrm{N}_{2}$ atmosphere. The selected spectral bands of interest cover the major absorbance modes of the toluene molecules. The other normal modes are either too weak to be observed or obscured by the vibration of the adsorbed water or of the clay structures. All assignments of the absorbance peaks for toluene were obtained from the literature [19]. In order to highlight the sorption spectra and improve their resolution shown in the following figures, only three frequency regions of interest were extracted from each spectrum.

Figure 2 shows the sorption spectra for the entire experimental period in three wavelength ranges for the three clays and the spectra of toluene liquid and vapor in three wavelength ranges.

Kaolinite. The spectra of the sorbed phase on kaolinite (Fig. 2) show the characteristics of toluene vapor, which implies that toluene molecules are only physically sorbed on this clay and that no strong interaction exists between toluene molecules and kaolinite. We describe this sorptive behavior as the labile (gaslike) phase and designate it as $L$-type sorption. Physical sorption has a low activation energy and is presumed to achieve equilibrium instantaneously. Our hypothesis of physical-only sorption is also supported by the observed fast sorption and desorption of toluene on kaolinite. In this study, the spectrum of sorbed toluene maintained the same shape from the beginning until the end of the sorption experiment. No sorbed residual could be found (not shown in the figures).

The relatively slow transfer through the sorbent-gas-phase boundary layer and the intra-aggregate diffusion have been considered to be a hindrance in the sorption process [20]. With
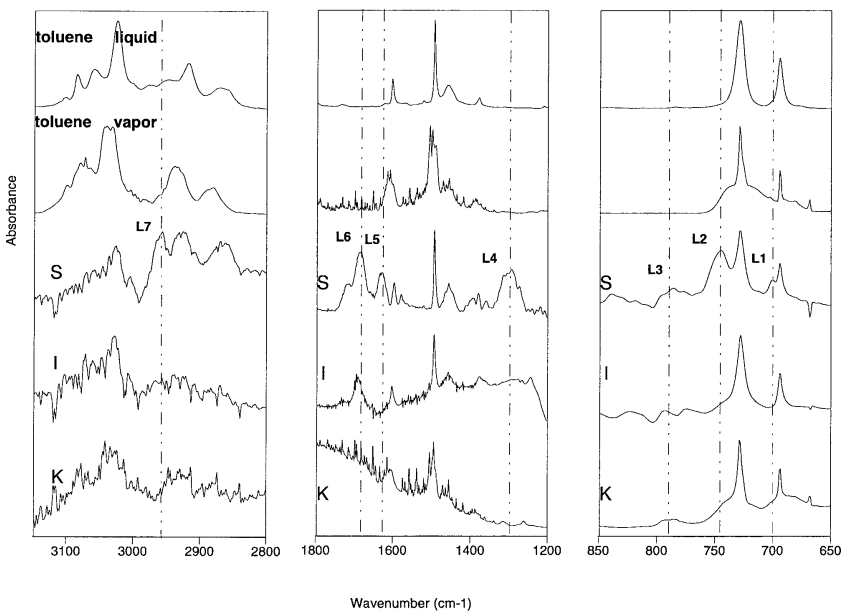

Fig. 2. Three selected Fourier transform infrared (FTIR) spectrum regions of the sorbed phases on clay samples at the end of the sorption experiment ( $14 \mathrm{~d}$ for kaolinite and illite and $16 \mathrm{~d}$ for montmorillonite) under low relative humidity with the spectra of toluene liquid and toluene vapor as references. The symbols S, I, and $\mathrm{K}$ denote montmorillonite (StxL), illite (IMtL), and kaolinite (KGaL). The symbols $\mathrm{L} 1$ to $\mathrm{L} 7$ represent the new bands that could be found in the spectrum of neither toluene liquid nor toluene vapor. The absorbance scale is arbitrary.

a flow rate of $50 \mathrm{ml} / \mathrm{min}$, the flow velocity of $\mathrm{N}_{2}$ gas in the cell was estimated to be higher than $10 \mathrm{~cm} / \mathrm{s}$. The thickness of the stagnant gas layer on the sorbent surface is estimated to less than $1 \mathrm{~mm}$. The time scale for toluene molecules to diffuse through this stagnant layer will be only $1 \mathrm{~s}$. In this part of the study, the highest sorbed amount was attained in about $30 \mathrm{~min}$. During the desorption experiment it also took about $30 \mathrm{~min}$ to remove the toluene completely from the kaolinite. Therefore, the mass transfer in the bulk gas phase is not a rate-limiting factor for sorption in this case.

Similarly, the retarded intra-aggregate diffusion with the clay film of only $5 \mu \mathrm{m}$ (estimated by dividing the dry sorbent volume with the planar area of the clay smear) will have a time scale of only $10^{-5} \mathrm{~s}$ with a retardation factor of about 1 , which was estimated by another study in our laboratory from the sorption equilibrium coefficient, the porosity, and the bulk density of the sorbent.

Possible rate-limiting processes would be the intrinsic sorption kinetics on the mineral surfaces because of the high activation energy and the physically hindered diffusion in the interstitial space in kaolinite. Further investigation is necessary to elucidate the mechanisms that retarded the sorption/desorption rate.

Illite. The pattern of the absorbance peaks of sorbed toluene on illite (Fig. 2) is similar to that of the liquid toluene (Fig. 2 ), which indicates that toluene molecules are largely sorbed through liquid condensation. Similar to the sorbed gas phase on kaolinite, this liquid phase occurred on illite from the beginning of the sorption experiment. However, it took about 1 $\mathrm{h}$ to achieve $95 \%$ equilibrium, which is longer than required for kaolinite. We describe this sorptive behavior as the slowsorption (liquidlike) phase and designate it as $S$-type sorption.

An absorbance peak belonging to neither toluene liquid nor toluene vapor was found in this experiment and designated new band L6. The peak shift due to the physical sorption of a compound is usually small (less than $2 \mathrm{~cm}^{-1}$ ) [11] compared to those for strong bond formation on chemical transformation. We termed this a new band because a significant wave-number 

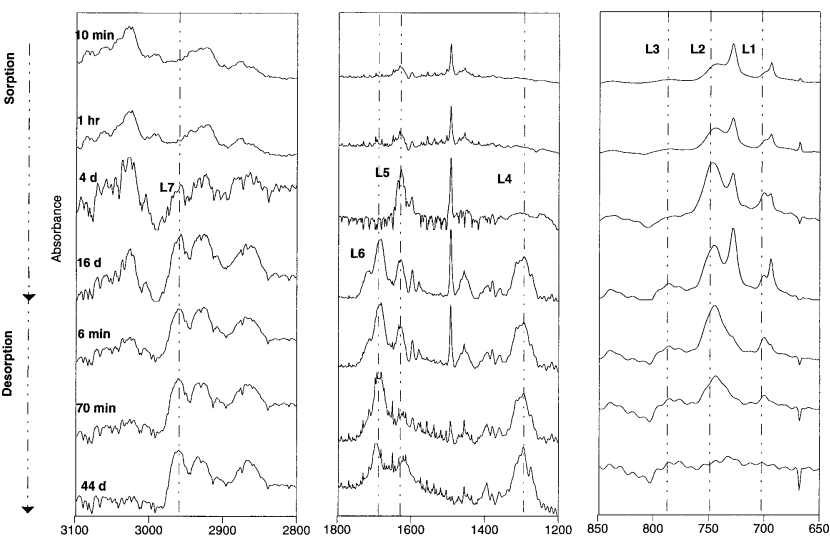

Wavenumber (cm-1)

Fig. 3. Fourier transform infrared (FTIR) spectra of the sorbed phases on montmorillonite after various stages of sorption and desorption under low relative humidity. The attenuation of the intensity of the spectra are adjusted to be the same as that for the 16-d sorption spectrum.

shift larger than $2 \mathrm{~cm}^{-1}$ occurred in both the sorption and the desorption spectra.

Band L6 did not appear until $9 \mathrm{~d}$ after the sorption experiment had started. It is possible that L6 is an absorbance peak of a transformed derivative from sorbed liquid toluene. Therefore, the sorbed phases on illite can be divided into two categories: a liquid toluene phase and one phase showing unassigned new band (L6) (Fig. 2). However, L6 is the only new band that could be determined in the spectrum for illite. It is suggested that L6 must be accompanied by other weak peaks that cannot be distinguished from the interfering peaks of the clay. The characteristic peaks of liquid toluene on illite disappeared after $4 \mathrm{~h}$ of desorption. The desorption rate of liquid toluene on illite is slower than that of the labile (gaslike) toluene on kaolinite. The formation represented by L6, however, was still sorbed on illite throughout the 4-d desorption experiment. The resistance to the stripping by nitrogen gas suggests that the vapor pressure of the new chemical form is much lower than that of toluene or that a stronger bond between the new chemical form and the clay may have been formed.

Montmorillonite. The sorbed phase on montmorillonite shows both toluene liquid bands and some new bands in the wave-number regions investigated (Fig. 2). In addition to band L6, which was found on illite, other new bands were identified.

The sorption and desorption rates of the sorbed liquidlike toluene on montmorillonite are similar to those on illite. The sorption rate, which may have been affected by liquid condensation as well, is lower than that of the vaporlike sorption that occurred on kaolinite. The $S$-type bands L1, L2, and L3, occurring with the sorbed liquidlike toluene, clearly appeared as soon as the sorption started. Compared with the wave number of other peaks on their right-hand side (729 and $694 \mathrm{~cm}^{-1}$ ), L1 and L2 have shifted to higher energy levels with ranges of 20 and $10 \mathrm{~cm}^{-1}$, respectively. No counterpeak was observed for L3 in the spectrum of liquid toluene. These three new bands fall in the region indicating aromatic carbon-hydrogen $(\mathrm{C}-\mathrm{H})$ bending and ring torsion, which is usually found for compounds with methyl-substituted benzene rings [21]. The large shift of these three bands suggests the existence of strong interaction between the sorbate and the mineral, which restricts the $\mathrm{C}-\mathrm{H}$ bending and the ring torsion.

The attenuation of the intensity of the spectra in Figure 3 was adjusted to be the same as that of the sorption spectrum for the 16-d sorption experiment, which is shown in the same figure for the purpose of comparison. The areas of L1 and L2 increased more slowly than their liquidlike counterparts. Moreover, the desorption rate of the new bands is also slower than the liquidlike sorbed toluene (Fig. 3). This type of sorption is obviously different from that of liquid condensation. It implies that this type of sorbing site is less accessible to toluene molecules. However, these new bands can be thoroughly removed by purging for about $5 \mathrm{~h}$. Chemisorption is unlikely to account for L1 and L2.

The other four new bands, L4, L5, L6, and L7, were not observed on montmorillonite until the sorption process had been carried on for $14 \mathrm{~d}, 27 \mathrm{~h}, 12 \mathrm{~d}$, and $4 \mathrm{~d}$, respectively. The left shoulder of L6 also appeared on the 14th day. We call these bands R (resistant)-type bands. The patterns of these bands were unlike those of toluene liquid. The difference was even more obvious after the sorbed toluene molecules were purged (shown in the desorption experiment of Fig. 3). No band with wave number higher than $3,000 \mathrm{~cm}^{-1}$ was observed, suggesting the absence of aromatic $\mathrm{C}-\mathrm{H}$ stretching. Band L7, located on the farthest left, could be assigned as the nonaromatic C-H stretching frequency $\left(<3,000 \mathrm{~cm}^{-1}\right)$. The L6, located at $1,700 \mathrm{~cm}^{-1}$, suggests the characteristics of carbonyl stretching. All this spectral information suggests new organic chemical structures formed in the Ca-montmorillonite. Carboxylation has been identified by Mortland and Boyd [22] in a chloroethane/Cu-montmorillonite system. Similarly, Camontmorillonite may also possess the catalytic ability to transform or degrade toluene under room temperature and dry conditions as long as sufficient contact time is available.

Among these four bands, only L5 could be removed with $\mathrm{N}_{2}$ gas in about $70 \mathrm{~min}$ (shown in the desorption experiment in Fig. 3). Both L7 and L4 persisted through the desorption experiment. The L6 kept transforming even with nitrogen purging. The intensity of the sorbed phase had not changed at all after $19 \mathrm{~d}$ of purging. Following a 25-d interruption in purging, while the intensities of L7 and L6 did not significantly change, another band in the neighborhood of the location of L5 appeared (shown by the desorption spectrum on the 44th day in Fig. 3). According to the differential desorption rate of new peaks, it is suggested that more than one new chemical species were formed. These persistent transformed products must have lower vapor pressure or stronger interaction with the minerals than toluene.

\section{Sorption and desorption under high $\mathrm{RH}$}

Among the three clays, montmorillonite and illite have significantly higher amount of sorbed toluene than that of kaolinite. Therefore, sorption experiments were performed for montmorillonite and illite under high RH conditions.

A significant amount of toluene was sorbed by montmorillonite starting at the initial period of sorption even under high RH (Figs. 4 and 5). Researchers have found that for montmorillonite moisture is bound primarily to the interlayer exchangeable cations and that the binding had only minor effects on the sorption of hydrophobic pollutants, such as the sorption of alkyl-substituted benzenes, on the siloxane surfaces $[16,17]$. Therefore, siloxane surfaces should still be accessible by the toluene molecules even under relatively high humidity.

According to the sorption and desorption rates of the sorbed phases (Figs. 4 and 5), the toluene-sorbed phases on montmorillonite include primarily $S$-type and $R$-type. Seven new 

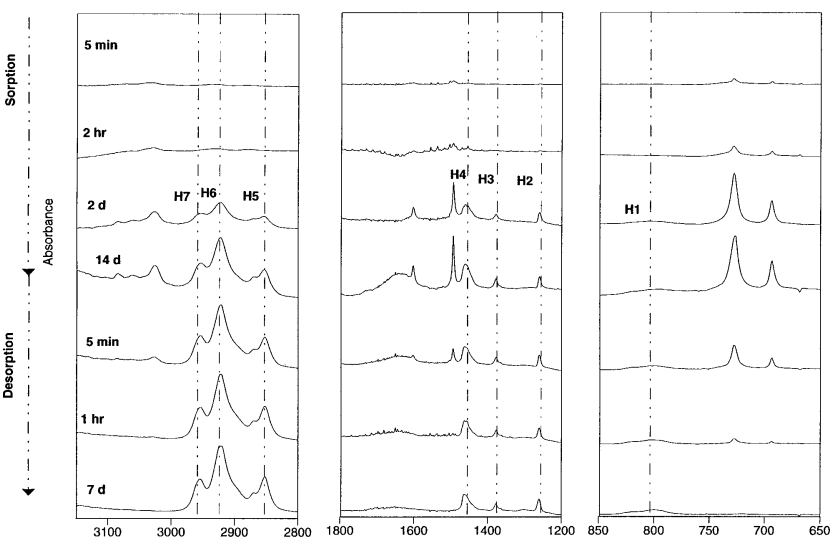

Wavenumber (cm-1)

Fig. 4. Fourier transform infrared (FTIR) spectra of the sorbed phases on illite after various stages of sorption and desorption under high relative humidity. The attenuation of the intensity of the spectra are adjusted to be the same as that for the 14-d sorption spectrum.

bands, with wave numbers different from those under low $\mathrm{RH}$, became obvious on illite ( $\mathrm{H} 1$ to $\mathrm{H} 7$ in Fig. 4 on the second day). Five new bands appeared for montmorillonite (H1, H2, and $\mathrm{H} 5$ to $\mathrm{H} 7$ in Fig. 5 on the third day). Possible assignments for these new bands are methyl $\mathrm{C}-\mathrm{H}$ stretching for $\mathrm{H} 7$ and $\mathrm{H} 6$, methylene $\mathrm{C}-\mathrm{H}$ stretching for $\mathrm{H} 5$, methyl bending for $\mathrm{H} 4$ and $\mathrm{H} 3$, carbon-oxygen $(\mathrm{C}-\mathrm{O})$ stretching for $\mathrm{H} 2$, and $\mathrm{C}-\mathrm{O}$ bending for $\mathrm{H} 1$. The attenuation of the intensity of the spectra shown in Figures 4 and 5 are adjusted to be the same as that for the 14-d sorption spectrum in Figure 4 and the 21-d sorption spectrum in Figure 5. From the day when the new bands appeared, the intensity of the adsorbed liquidlike toluene remained nearly constant through the sorption experiment. However, the intensity of the new bands (except for $\mathrm{H} 2$ on illite) increased gradually.

\section{Sorption kinetics and mechanisms}

The amount of toluene sorbed on the clay initially increased quickly and then slowly approached equilibrium. A first-order rate constant was used to describe the sorption kinetics. The sorption rate is assumed to increase with the difference be-
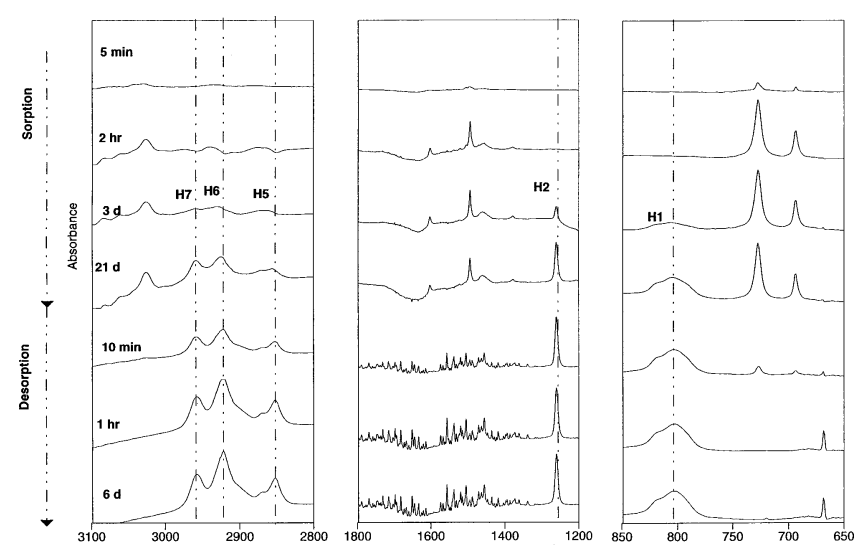

Fig. 5. Fourier transform infrared (FTIR) spectra of the sorbed phases on montmorillonite after various stages of sorption and desorption under high relative humidity. The attenuation of the intensity of the spectra is adjusted to be the same as that for the 21-d sorption spectrum. tween sorption amount on clay and the equilibrium amount. According to Beer's law, the concentration of IR-absorbing component depends on its absorbance. The absorbance area of toluene's characteristic peak $694 \mathrm{~cm}^{-1}$ was used to determine the concentration. The rate constant, $k_{a}$, is calculated as $d A / d t=-k_{a}\left(A-A_{e}\right)$, where $A$ is the integration area of peak $694 \mathrm{~cm}^{-1}$ at time $t$ and $A_{e}$ is the integration area of peak 694 $\mathrm{cm}^{-1}$ at sorption equilibrium. For low RH condition, $k_{a}$ is 1.1 , 0.20 , and $0.29 \mathrm{~h}^{-1}$ for kaolinite, illite, and montmorillonite, respectively. For high RH condition, $k_{a}$ is 0.05 and $0.14 \mathrm{~h}^{-1}$ for illite and montmorillonite, respectively. It is suggested that the sorption rate under low $\mathrm{RH}$ is faster than that under high $\mathrm{RH}$, and $L$-type sorption, which was found largely on kaolinite, shows a faster rate than $S$-type sorption found on illite and montmorillonite.

The variation of sorption behaviors found that the three clay samples may be attributed to the different clay structures. Since kaolinite has the lowest specific surface area (Table 1), it implies that kaolinite lacks micropores or mesopores and that toluene sorbed on kaolinite is primarily the gaslike type rather than liquidlike (multilayer) type. The binding force between the silicate sheets of montmorillonite is weaker than kaolinite. Therefore, the loosely bound silicate sheets of montmorillonite contribute more surface area and micropores or/ and mesopores. The pores provide thermodynamically favorable environments for toluene condensation and entrapment. It is one possible cause of the domination of the liquidlike spectrum for montmorillonite.

Adsorption or inclusion of adsorbate into small pores at nanometer dimensions brings the molecules and clay matrixes in close proximity, which may lower the activation energy of possible reactions [23]. Therefore, transformation products were produced following the occurrence of liquidlike phase on illite and montmorillonite. The possible reactions include benzene ring opening (FTIR spectra for aromatic $\mathrm{C}-\mathrm{H}$ disappearing), oxidation (carbonyl or C-O appearing), and alkylation ( $\pi$ bond disappearing).

Slow sorption and desorption are found under high $\mathrm{RH}$ conditions as well as under low RH conditions. Infrared spectra under both low and high RH conditions provide evidence of toluene transformation. However, aging changes the sorption behavior and results in the resistant-to-desorption phase for both low and high RH conditions. Slow appearance of sorption products indicates a high activation energy for the chemisorption process.

\section{Quantitative information of the residual transformed products}

The absorbance areas, due to $\mathrm{C}-\mathrm{H}$ stretching, from 3,130 to $3,000 \mathrm{~cm}^{-1}$ and 2,992 to $2,800 \mathrm{~cm}^{-1}$ of the sorption spectra for the full-term experiment were used to estimate the ratio of the abundance of the residual transformed products to the adsorbed toluene. Some part of the absorbance area in the range of 2,800 to $2,992 \mathrm{~cm}^{-1}$ that overlapped with toluene absorbance were subtracted to obtain the net absorbance of the residual transformed products, while the molar absorsivity for these two bands were assumed equal. Table 2 shows the sorption ratios under both low and high $\mathrm{RH}$. For montmorillonite, the ratios under different RH are generally the same. However, it is higher for illite under high RH than under low RH.

Although it is known that the sorption on clays is inhibited by water vapor [24], it seems that water cannot completely hinder the catalytic ability of clay. 
Table 2. The sorption ratio of residual transformed products to the adsorbed toluene on illite and montmorillonite for the full-term experiments ${ }^{\mathrm{a}}$

\begin{tabular}{lcc}
\hline & Low RH & High RH \\
\hline Illite & No observable transformed product & 2.34 \\
Montmorillonite & 0.21 & 0.18 \\
\hline
\end{tabular}

a The data were derived from the infrared (IR) absorbance area among the range from 3,130 to $2,800 \mathrm{~cm}^{-1}$. The ratio of the residual transformed products on illite under low relative humidity $(\mathrm{RH})$ was not estimated because of the insignificant absorbance of adsorbed toluene in this range.

\section{Catalytic ability of clay}

Clay is known for its catalytic ability and used as catalysts or promoters in organic reactions, especially under heated conditions, to obtain products of interest at economic yields [25]. But the catalytic ability of clay for pollutants under conditions similar to the natural environment is not well understood. Furthermore, pollutants are often in contact with soil at time scales of days to years, which is longer than the typical time scale of minutes to hours for the investigation of organic reactions by using clay.

Some researchers have shown that the interlamellar region of montmorillonite provides sites for chemisorption (see Introduction); that is, organic molecules are allowed to enter the interlamellar space and stay in it. The interlamellar space may provide an environment for toluene molecules to undergo stronger binding or chemical transformation. Although illite (hydrous mica) is nonswelling, some transformed products were also found on illite. It is postulated that mica, a component of illite, is often intercalated with other minerals and commonly present as components of particles that have been partially transformed to expansible minerals [26], which may contribute to the similar results as in montmorillonite.

The chemical transformation rate of $\mathrm{Ca}$-montmorillonite in this study is obviously lower than that of $\mathrm{Cu}$-montmorillonite as reported by others. It took days to transform toluene on $\mathrm{Ca}$ montmorillonite in this study but only several minutes to transform $p$-xylene on $\mathrm{Cu}$-montmorillonite reported by others [13]. It is possibly due to the energy gain of the d-orbital occupation of calcium being not high enough for the benzyl ring to transfer electrons to and undergo the single electron transfer reaction. Micropores and/or the high specific surface area of clay are considered effective factors for the catalytic efficiency of clay, which is usually used to produce desired products [25]. No observable transformation products for kaolinite may be due to its lower specific surface area.

\section{CONCLUSIONS}

Both the clay content and clay type are important factors affecting the physical sorption and chemical transformation behavior of volatile organic pollutants in soil environments. Although the experiments performed under short-term and extremely dry conditions using modified copper-exchanged clay have shown chemical transformation of organic pollutants [1214], the long-term observation for the calcium-exchanged clay under both high and low RH conditions has not been reported before.

This study has shown that clay serves as both a pollutant adsorbent and a chemical transformation mediator. The results of long-term observations in this study have revealed the existence of abiotic natural attenuation of toluene on clays, which are typical soil constituents. For a contaminated site where no practical remediation technique is feasible, monitored natural attenuation could be a possible alternative. Constructing a layer of clay around a contaminated site may provide an active barrier to transform the pollutants to some extent as well as to retard the movement of pollutants.

Acknowledgement-The authors gratefully acknowledge the financial support of the National Science Council, ROC (Contract NSC 882211-E-002-013).

\section{REFERENCES}

1. Luthy RG, Aiken GR, Brusseau ML, Cunningham SD, Gschwend PM, Pignatello JJ, Reinhard M, Traina SJ, Weber WJ Jr, Westall JC. 1997. Sequestration of hydrophobic organic contaminants by geosorbents. Environ Sci Technol 31:3341-3347.

2. Alexander M. 2000. Aging, bioavailability, and overestimation of risk from environmental pollutants. Environ Sci Technol 34: 4259-4265.

3. Loehr RC, Webster MT. 1996. Behavior of fresh vs. aged chemicals in soil. J Soil Contam 5:361-383.

4. Nam K, Chung N, Alexander M. 1998. Relationship between organic matter content of soil and the sequestration of phenanthrene. Environ Sci Technol 32:3785-3788.

5. Li H, Lee LS. 1999. Sorption and abiotic transformation of aniline and $\alpha$-naphthylamine by surface soils. Environ Sci Technol 33: 1864-1870.

6. Li Y, Gupta G. 1994. Adsorption/desorption of toluene on clay mineral. J Soil Contam 3:127-135.

7. Farrell J, Grassian D, Jonse M. 1999. Investigation of mechanisms contributing to slow desorption of hydrophobic organic compounds from mineral solids. Environ Sci Technol 33:1237-1243.

8. Schlebaum W, Schraa G, van Riemsdijk WH. 1999. Influence of nonlinear sorption kinetics on the slow-desorbing organic contaminant fraction in soil. Environ Sci Technol 33:1413-1417.

9. Arocha MA, Jackman AP, McCoy BJ. 1996. Adsorption kinetics of toluene on soil agglomerates: Soil as a biporous sorbent. Environ Sci Technol 30:1500-1507.

10. Fenn DB, Mortland MM, Pinnavaia TJ. 1973. The chemisorption of anisole on $\mathrm{Cu}(\mathrm{II})$ hectorite. Clay Clay Miner 21:315-322.

11. Pinnavaia TJ, Mortland MM. 1971. Interlamellar metal complexes on layer silicates. 1. copper(II)-arene complexes on montmorillonite. Journal of Physical Chemistry 75:3957-3962.

12. Boyd SA, Mortland MM. 1986. Radical formation and polymerization of chlorophenols and chloroanisole on copper(II)-smectite. Environ Sci Technol 20:1056-1058.

13. Govindaraj N, Mortland MM, Boyd SA. 1987. Single electron transfer mechanism of oxidative dechlorination of 4-chloroanisole on copper(II)-smectite. Environ Sci Technol 21:1119-1123.

14. Johnston CT, Tipton T, Trabue SL, Erickson C, Stone DA. 1992. Vapor-phase sorption of $p$-xylene on $\mathrm{Co}$ - and $\mathrm{Cu}$ - exchange $\mathrm{Saz}$ 1. Environ Sci Technol 26:382-390.

15. Hinedi ZR, Johnston CT, Erickson C. 1993. Chemisorption of benzene on $\mathrm{Cu}$-montmorillonite as characterized by FTIR and ${ }^{13} \mathrm{C}$ NMR. Clay Clay Miner 41:87-94.

16. Sheng G, Boyd SA. 1998. Relation of water and neutral organic compounds in the interlayers of mixed $\mathrm{Ca}$ /trimethylphenylammonium-smectite. Clay Clay Miner 46:10-17.

17. Stevens JJ, Anderson SJ, Boyd SA. 1996. FTIR study of competitive water-arene sorption on tetramethylammonium and trimethylphenylammonium-montmorillonite. Clay Clay Miner 44: 88-95.

18. Xu S, Lehmann RG, Miller JR, Chandra G. 1998. Degradation of polydimethylsiloxanes (silicones) as influenced by clay minerals. Environ Sci Technol 32:1199-1206.

19. Lau CL, Snyder RG. 1971. A valence force field for alkyl benzenes -toluene, $p$-xylene, $m$-xylene mestilyene, and some of their deuterated analogues. Spectrochim Acta 27A:2073-2088.

20. Wu SC, Gschwend PM. 1986. Sorption kinetics of hydrophobic organic compound to nature sediments and soil. Environ Sci Technol 20:717-725.

21. Nakanishi K, Solomon PH. 1977. Infrared Absorption Spectroscopy, 2nd ed. Holden-Day, San Francisco, CA, USA.

22. Mortland MM, Boyd SA. 1989. Polymerization and dechlorina- 
tion of chloroethenes on $\mathrm{Cu}(\mathrm{II})$-smectite via radical-cation intermediates. Environ Sci Technol 23:223-227.

23. Izumi K, Urabe K, Onaka M. 1992. Zeolite, Clay, and Heteropoly Acid in Organic Reactions. Kodansha, Tokyo, Japan.

24. Chiou CT, Soup TD. 1985. Soil sorption of organic vapors and effects of humidity on sorptive mechanism and capacity. Environ Sci Technol 19:1196-1200.

25. Balogh M, Laszlo P. 1993. Organic Chemistry Using Clays. Springer-Verlag, New York, NY, USA.
26. Bohn HL, McNeal BL, O’Connor GA. 1985. Soil Chemistry. John Wiley, New York, NY, USA.

27. Olphen HV, Fripiat JJ. 1979. Data Handbook for Clay Materials and Other Nonmetallic Minerals. Pergamon, New York, NY, USA.

28. Weissmahr KW, Haderlein SB, Schwarzenbach RP. 1998. Complex formation of soil minerals with nitroaromatic explosives and other $\pi$-acceptors. Soil Sci Soc Am J 62:369-378. 